\title{
Les sécheresses de 1989 et 1990
}

\author{
The 1989 et 1990 droughts
}

La sécheresse exceptionnelle des deux années consécutives 1989 et 1990 et dans une moindre mesure celle de 1991 a eu des conséquences importantes sur les fondations des constructions moyennes ou légères. L'expérience ainsi acquise a permis au Comité Français de Géologie de l'Ingénieur de rassembler quatre articles traitant des différents aspects, physique et mécanique, légaux ou réglementaires, qui complètent l'article de G. PHILIPPONNAT paru dans le $n^{\circ} 57$ de la Revue Française de Géotechnique. Il nous a paru intéressant de les grouper pour les présenter à nos lecteurs.

P. HABIB

Directeur de la Publication 